\title{
Impacts of demand side management programs to domestic hot water heating load profiles in smart buildings
}

\author{
Jari Pulkkinen Jean-Nicolas Louis \\ Water, Energy and Environmental Engineering, University of Oulu, Finland, \\ jari.pulkkinen@oulu.fi jean-nicolas.louis@oulu.fi
}

\begin{abstract}
The increasing amount of variable electricity generation has brought world to investigate various flexibility sources to provide power network balancing through demand side management. Therefore, it is important to create new, more thorough models that allow using smart functions to control the various electricity loads. In this paper a model to simulate a fully mixed domestic hot water tank's behavior in 60,30 and $15 \mathrm{~min}$ time resolution, and its control mechanisms were created. The model will be integrated to another smart house model to enable studying more combined smart controls and functions. Additionally, the flexibility of the hot water storage tank was investigated with the help of 4 different heating scenarios, showing its suitability for Demand Side Management, and the operation of the model was confirmed with lower time resolutions.

Keywords: domestic hot water, demand side management, smart building, exploratory scenario
\end{abstract}

\section{Introduction}

The increasing electricity generation from variable renewable energy sources creates new requirements for balancing the demand and supply of electricity. To prevent imbalance issues on the network, new kinds of balancing mechanisms are being studied, one of which is to utilize the flexible loads on the demand side to shift electricity consumption according to its supply status. In residential buildings deferrable and thermal loads, like domestic hot water (DHW) storages, are generally considered as good sources for providing flexibility to the network ( $\mathrm{Lu}$, 2012). These loads can be used to participate in Demand Side Management (DSM) programs where electricity consumers adjust their electricity consumption to match the status of power network either through price-signals, like Time-of-Use (ToU) or Real-time price (RTP), or by receiving an incentive payment when reacting to a request to reduce electricity consumption (US Department of Energy, 2006). Additionally, combining local electricity generation from e.g. Photovoltaic-panels with flexible electricity loads can help in increasing self-consumption from local electricity generation and provide monetary benefits (Salpakari and Lund, 2016). Therefore, there is a need to identify and study the flexibility in buildings to determine suitable sources and their potentials in participating in DSM programs, through programs like IEA EBC Annex 67 Energy Flexible Buildings (Jensen et al., 2017).

\subsection{Domestic Hot Water}

Domestic hot water (DHW) is an important part of having a good living quality and technology to produce and store it are essential in today's world. Hot water is commonly mixed with colder tab water to create thermally comfortable water to be used in shower or as tab water to wash hands. As the consumption of DHW is not constant, it is important to study both their load profiles and the behavior and sizing of DHW storage systems (Ahmed et al., 2016) considering that it needs to be available for use when requested. Fuentes et al. (2018) highlighted the importance of having relevant information about DHW withdrawal profiles and to consider them as a foundation on designing novel control strategies for DHW storage tanks. In addition to having representative load profiles, it is also important to model the thermal behavior of DHW tanks, so that it is possible to simulate these new control strategies, especially on different temporal resolutions. Currently there is an abundance in created DHW models, e.g. (Paull et al., 2010; Baeten et al., 2016; Jack et al., 2018) with different levels of detail (e.g. is stratification taken into account) (Jack et al., 2018). Additionally, there are also lot of different control strategies already created for utilizing DHW in DSM programs (Atikol, 2013; Jack et al., 2018; Paull et al., 2010). As there starts be more interest towards smart houses and full building control on smaller time resolutions, it is important to develop DHW models that can be integrated with other building-level models to ensure the potential for developing full building level control schemes and enable better participation to DSM programs.

\subsection{Aims and objectives}

The aim of the work is to create a DHW model with electric heating to be integrated into an existing Markov-Chain smart house model ${ }^{1}$ (Louis et al., 2016) and study the impacts of various DSM programs to the electricity load profile of the heating of DHW tank. Therefore, the interoperability of the created DHW and existing smart house models need to be kept in mind during the creation of the model. Also, load shifting and other DSM tools are tested

${ }^{1}$ (https://github.com/jeanlouisnico/sBuM) 


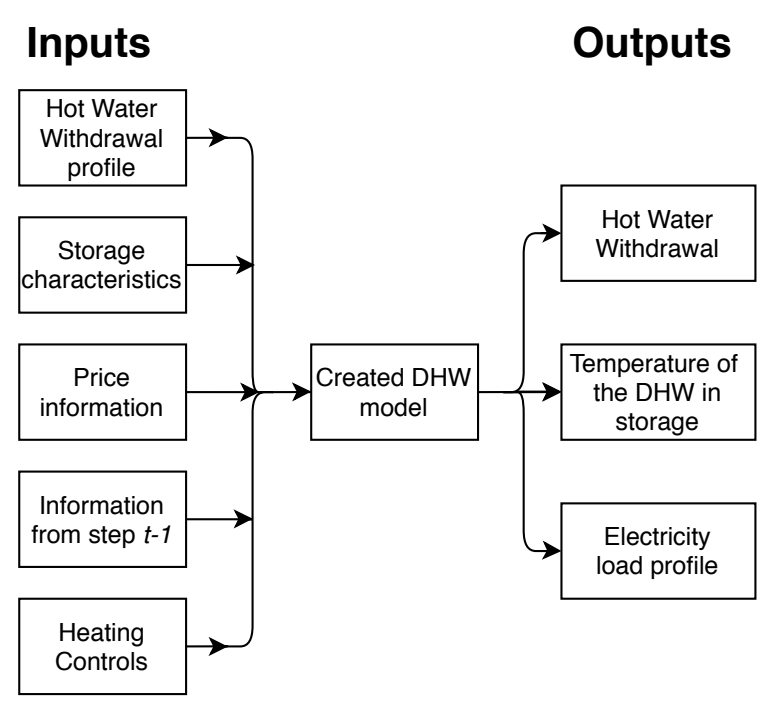

Figure 1. Basic description of the DHW model

to investigate the flexibility of electrically heated hot water storage tank. Finally, the results from the smart house model (Louis et al., 2016) and the created DHW model are investigated and compared on their load profiles as well as the potential to integrate the models.

\section{Methodology}

The created DHW model includes three separate parts: draw-off profile of hot water from the storage tank, temperature of hot water in the tank and heating schedules of the DHW. These parts allow modeling the behavior of the DHW tank to determine the electricity load profile and apply the control methods for various DSM programs. The model is created to be integrated in an existing smart house model (Louis et al., 2016) to study the electricity load management and potential DSM methods on building-level. Moreover it should provide more information about the building's thermal behavior and append the model's thermal part (Pulkkinen et al., 2019), while eventually enabling a more thorough control of electric heating in the building. There is also an on-going work to develop the smart house model to operate on a temporal resolution of $30,15,1$ minute and even in $10 \mathrm{~s}$ timesteps. Therefore, it is important to follow this development to ensure the interoperability of these models.

The basic principle of the DHW model is presented in Figure 1. Basically, the model includes information on hot water demand, storage characteristics, price information and heating controls as separate inputs, while containing information about the previous simulation step (DHW temperature, heating load, etc.) for the use of the model. This provides the wanted outputs on the hot water withdrawal, temperature of the hot water and electricity load profile.

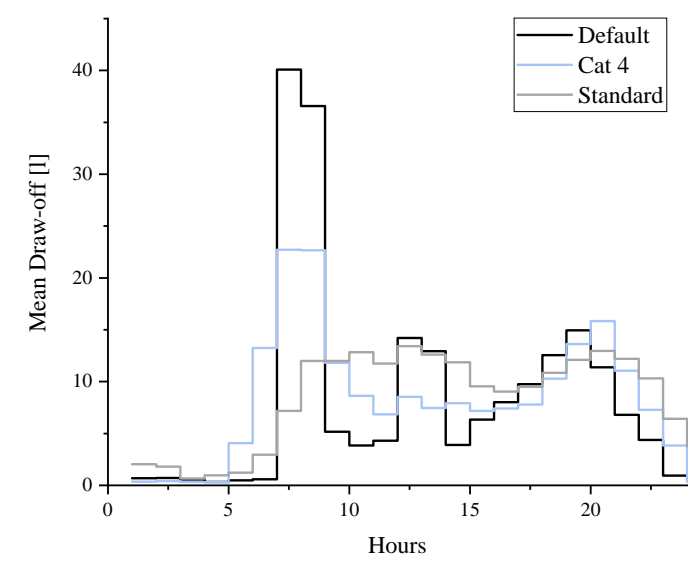

Figure 2. Mean hourly draw-off profiles of the created 3 different $60 \mathrm{~min}$ load profiles (Default, 4 Categories option from Jordan and Vajen (2001) and load profile created from standard EN 12831-3).

\subsection{Hot Water Demand Profile}

The hot water demand profiles for the model were created with using DHWcalc program, which creates realistic DHW load profiles using statistical methods on various temporal resolutions (Jordan and Vajen, 2001). Therefore, it was selected as a suitable tool for testing the created DHW model and its capability in running simulation on the created 60,30 and $15 \mathrm{~min}$ timesteps. To ensure the capabilities of the DHW model, 3 different load profiles were created for each timestep, all for the length of one year. The first profile is the default profile created with default values from the program, while the second profile is created by inserting the hourly test profile for singlefamily houses from standard EN 12831-3 (2017) as stepfunction to the program. The third profile is created with the values from the 4 different categories option from the software, presenting default distribution per IEA-Task 26. The average daily DHW draw-off is 200 litres in each scenario and the mean hourly draw-offs for the created 60 min profiles are presented on Figure 2. The created profiles seem to have different characteristics as the Default load profile varies more on hourly basis and creates higher peaks than the other 2. Conversely, the load profile by the values from the standard has more balanced consumption during the day and has lower peaks. Additionally, the average 30 and 15 min draw-off profiles are presented in Figure 3, showing their different characteristics, and importance in simulating different time resolutions. In all cases, there were high morning peaks and 2 lower demand peaks, one around midday and the second in the evening.

\subsection{Hot Water Tank}

The model for DHW tank is created based on standards EN 15316-5 (2017) and EN 12831-3 (2017), and it is used to calculate the temperature of the hot water in the tank, stand-by heat losses and energy demand by utilizing energy balance method. The simplified calculation procedure with single volume and constant temperature 


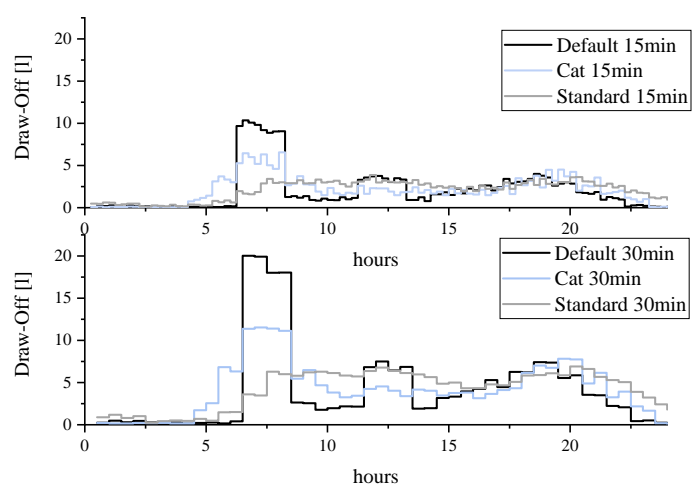

Figure 3. Mean draw-off profiles of the created 3 different 30 and 15 min load profiles

throughout the tank was selected as the tank is assumed to be constantly mixed having therefore a uniform temperature profile throughout the tank.

The average temperature of the water $T_{D H W}$ in the DHW tank is calculated with Equation 1:

$$
T_{D H W}=T_{D H W, 0}+\frac{P_{D H W} \times t_{c i}-Q_{D H W, o u t}-Q_{s t o, l s}}{\rho_{w} \times C_{p ; w} \times V_{s t o ; t o t}}
$$

where $T_{D H W, 0}$ is the water temperature from last simulation step $\left[{ }^{\circ} \mathrm{C}\right], P_{D H W}$ is the heating power $[W], t_{c i}$ is the calculation interval $[h], Q_{D H W, o u t}$ is the energy amount withdrawn from the tank [Wh], $Q_{s t o, l s}$ is the stand-by heat loss from the tank $[\mathrm{Wh}], \rho_{w}$ is the density of water $\left[\frac{\mathrm{kg}}{\mathrm{l}}\right]$, $C_{p ; w}$ is the specific heat capacity of water $\left[\frac{W h}{k g \times C}\right]$ and $V_{\text {sto,tot }}$ is the total volume of the DHW storage tank [l] (EN 15316-5, 2017). Heating power for the DHW tank is determined according to the DHW heating part of the model, while energy withdrawn $Q_{D H W \text {.out }}$ from the DHW tank is calculated with Equation 2 and the stand-by energy loss $Q_{s t o, l s}$ is calculated with Equation 3:

$$
\begin{gathered}
Q_{D H W, \text { out }}=V_{d, t} \times C_{p ; w} \times \rho_{w} \times\left(T_{D H W, r e f}-T_{\text {in }}\right) \times t_{c i} \\
Q_{s t o, l s}=f_{b a c, a c c} \times f_{d i s, l s} \times H_{s t o, l s} \times\left(T_{D H W}-T_{a m b}\right) \times t_{c i}
\end{gathered}
$$

where $V_{d, t}$ is the volume of the draw-off at time $t[l]$, $T_{D H W, \text { ref }}$ is the reference hot water temperature needed to create correct tab water temperature $\left[{ }^{\circ} \mathrm{C}\right] T_{\text {in }}$ is the temperature of the inlet water to the tank $\left[{ }^{\circ} \mathrm{C}\right], f_{\text {bac }, a c c}$ is the weighting factor for control and size of the tank [-], $f_{\text {dis }, l s}$ is weighting factor to correct the additional heat losses due to thermal bridges from the connecting pipes [-] and $T_{a m b}$ is the ambient temperature $\left[{ }^{\circ} \mathrm{C}\right]$ (modified from EN 15316-5 (2017) and EN 12831-3 (2017)).

\subsection{Heating Demand}

The basic principle for calculating the heating demand of the DHW tank and the resulting hot water temperature is presented in Figure 4. The model starts with calculating the temperature of the hot water in the tank if no heating

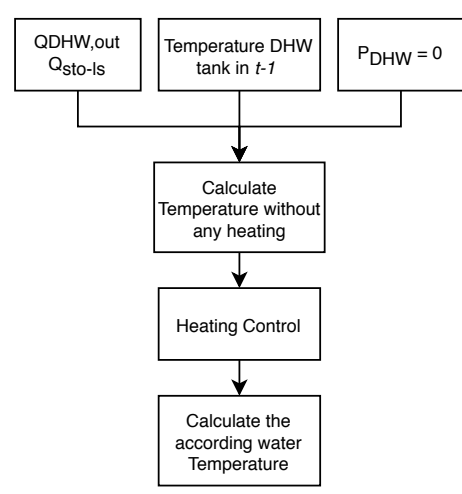

Figure 4. The calculation procedure for the created DHW model

would be used. That information, among with the other inputs, is then delivered to the control part of the model to determine the heating profile of the tank. After that, the temperature of the hot water in the tank is calculated according to the heating power assigned to the tank from the previous step.

\subsection{Heating Control}

The heating of the DHW tank is determined in a separate part of the model according to the rules of the selected heating scenario. There are currently 4 different heating scenarios available on the model, which each has their own control mechanism and rules. The available scenarios are Constant Temperature Set-point, On-Off Control, Time-of-Use Control and Linear Optimization, of which the control rules of the first three are presented in Figure 5. All the scenarios take into account upper and lower temperature limits $\left(T_{\min }\right.$ and $\left.T_{\max }\right)$ as well as maximum heating power $\left(P_{\max }\right)$ as constrains in determining the heating profile. The lower temperature limit $T_{\min }$ is considered to be the minimum healthy temperature of water to prevent the growth of Legionella bacteria. All these variables can be determined by the user allowing the possibility to study the impact of them to the heating profile.

\subsubsection{Constant Temperature Set-point}

The first studied heating scenario is Constant Temperature Set-point, which control options aim in keeping a steady temperature inside the DHW tank. The rules for the controller are explained in Figure 5a) where the temperature set-point is called $T_{\min }$ and the maximum heating capacity $P_{\max }$ is considered as the second constrain.

\subsubsection{On-Off Controller}

The second heating scenario is On-Off Controller, which represents a control relay with 2 temperature set-points. The control rules for this scenario are presented in Figure $5 \mathrm{~b}$ ) and it operates only with full heating power until the upper temperature set-point $T_{\max }$ is reached, after which the heating only turns on after the hot water temperature drops under the lower temperature set-point $T_{\min }$. In case the temperature set-points are reached in the on-going simulation time-frame, the power needed to meet them is 


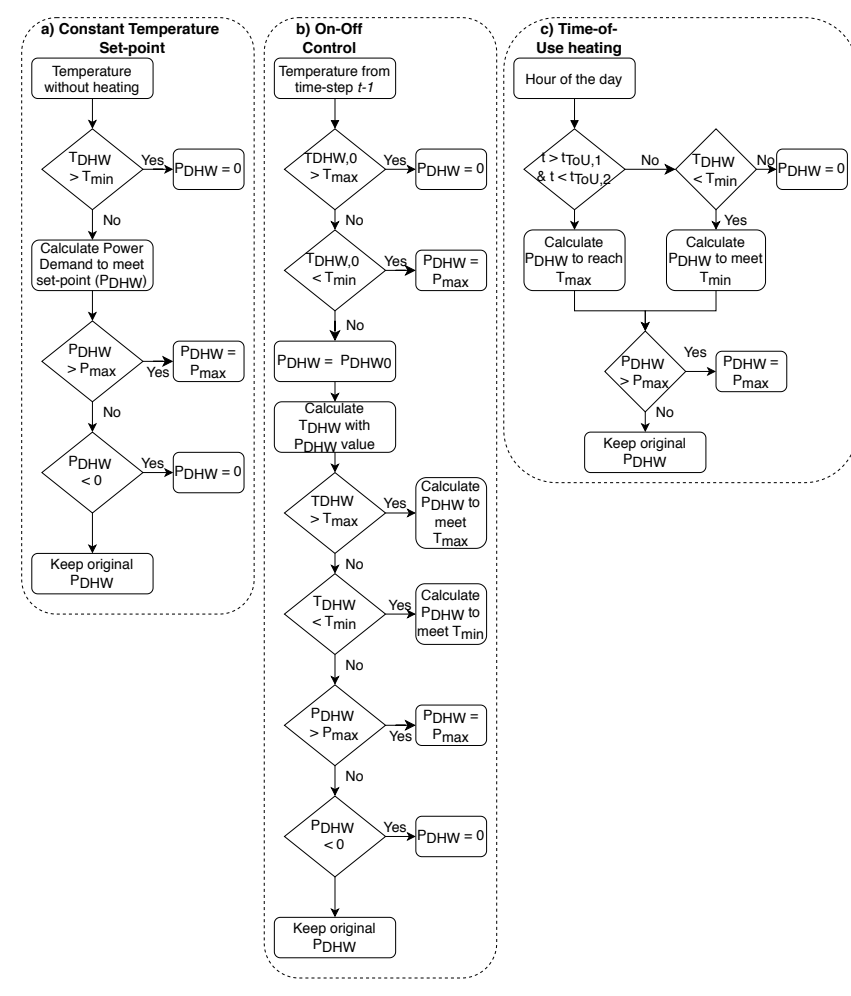

Figure 5. Presentation of the used rules in Constant (a), On-Off (b) and ToU (c) scenarios

calculated by solving $P_{D H W}$ from equation 1 when $T_{D H W}$ is $T_{D H W, \min }$ or $T_{D H W, \max }$ depending on the heating period, and the resulting power $P_{D H W}$ is considered as the heating power for the time-step. This is a simplified representation of the real world On-Off controller as here the temperature set-points are always reached in the simulation time-steps (e.g. full hour) whereas in real-world the temperature could have already dropped under or increased over the temperature set-points when the measurement for the time-step is conducted. Therefore, this type of On-Off controller would be required to have an embedded smartness in it that would make the system meet the temperature set-point exactly at the simulation time period.

\subsubsection{Time-of-Use Heating}

The third heating scenario is Time-of-Use Heating, which participates in DSM by optimizing heating with a ToU price signal and using water as an energy storage medium. Generally, ToU represents a scenario where electricity price is divided to high and low price periods according to the times of high and low electricity demand periods, guiding electricity users to consume electricity during the lower price times. This is also the used rule in the heating scenario presented in Figure 5c). The main idea is that hot water is heated to and kept on the upper temperature set-point on the time of the lower electricity price, and not heated during the higher price period unless the hot water temperature drops under the lower temperature set-point, after which it is only heated up to keep the hot water temperature at the lower temperature set-point.

\subsubsection{Linear Optimization}

The fourth studied heating scenario is Linear Optimization of the electrically heated hot water tank according to hourly RTP signal and heat demand. This is another type of DSM action where the electricity load profile is varied according to the real time situation of the electricity network while maintaining an acceptable hot water temperature in the storage tank to ensure comfort and health of the user. The optimization goal is to minimize the electricity cost (Equation 4) with the constrains from Equation 5.

$$
\begin{array}{r}
\min \sum \operatorname{Cost}_{1-n}=E_{D H W, 1-n} \times \text { Price }_{1-n} \\
\text { Constrains : } T_{\min } \leq T_{D H W} \leq T_{\max } ; 0 \leq P_{D H W} \leq P_{\max }
\end{array}
$$

where $\operatorname{Cost}_{1-n}$ is the cost from electricity usage from timesteps $1-n[€], E_{D H W, 1-n}$ is the energy used in timesteps $1-n\left[\mathrm{MWh}\right.$ and Price $_{1-n}$ is the real time price of electricity during the same timesteps [€/MWh]. The $T_{D H W}$ is calculated with Equation 1, to which also forecasted hot water demand is added. The optimization period $n$ can be determined by the user, but values of over 4 timesteps start to become slow computing-wise. For instance, linear optimization simulation with optimization period of 4 timesteps takes 495 s for hourly values for a year (8760 simulation steps), whereas optimization periods of 3 and 5 timesteps take 377s and 663s respectively for the same input data. This would still allow optimizing the system on real-time with the optimization period of 4 or 5 timesteps, but the difficulty in applying it to practice comes from the uncertainty in determining the draw off profile from the DHW tank as estimating the energy draw off correctly is vital to the correct optimization.

\subsection{Inputs}

The inputs values for testing the DHW behavior and DSM potential are defined on Table 1 underneath from the Decree 1010/2018 ${ }^{2}$, and the international standards EN 15316-5 (2017). Some input values vary depending on the heating scenario, while others stay the same during all the simulations.

The minimum requirement for the DHW in EN 153165 (2017) is considered as $55^{\circ} \mathrm{C}$, which is also the lower temperature setpoint used in the simulation, except for the Constant Temperature Set-point scenario where a temperature set-point of $60{ }^{\circ} \mathrm{C}$ was used to balance the otherwise occurring lower average temperature. The hourly Elspot price for Finnish transmission area in 2016 (Nord Pool, 2018) was selected as the price signal and the forecasted Hot Water Demand was created based on the test profile for single-family houses from EN 12831-3 (2017). The stand-by heat losses were calculated according to EN 15316-5 (2017), EN 60379 (2004) and EN 50440 (2015) by assuming a vertically adjusted and electrically heated DHW tank.

\footnotetext{
${ }^{2}$ Ympäristöministeriön asetus uuden rakennuksen energiatehokkuudesta 1010/2018, Decree of the Ministry of the Environment on the energy efficiency of new building 1010/2018
} 
Table 1. Input values for the simulation (EN 15316-5, Decree 1010/2018)

\begin{tabular}{ll}
\hline Variable & Value \\
\hline Hot Water Tank Volume & $300 \mathrm{l}$ \\
Max Power & $3 \mathrm{~kW}$ \\
Inhabitants & 4 \\
Average DHW demand & $50 \frac{l}{\text { inh }}$ \\
Inlet Water Temperature & $10{ }^{\circ} \mathrm{C}$ \\
Ambient air temperature & $16{ }^{\circ} \mathrm{C}$ \\
Default $T_{D H W}$ and $T_{\text {in }}$ difference & $45^{\circ} \mathrm{C}$ \\
$T_{\min }$ for Constant Temp Set & $60^{\circ} \mathrm{C}$ \\
$T_{\text {min }}$ for On-Off, ToU and Optimization & $55^{\circ} \mathrm{C}$ \\
$T_{\max }$ for On-Off & $655^{\circ} \mathrm{C}$ \\
$T_{\max }$ for ToU and Optimization & $85^{\circ} \mathrm{C}$ \\
ToU heating hours & $22-6$ \\
LP optimization period (timesteps ahead) & 4 \\
\hline
\end{tabular}

\section{Results}

The results firstly investigate the suitability of integrating the created model to the existing Markov-Chain smart house model by presenting the capability of operating in similar time resolutions and providing useful and robust results. Secondly, the behaviour of the DHW heating controls are examined in the 4 hourly heating scenarios. After that, the flexibility of DHW heating is investigated and the effectiveness of various control and DSM mechanisms are presented. The final part shows the combined effect of the two models in order to present the importance in integrating the smart house and DHW models.

\subsection{Robustness of the results}

The robustness of the results is looked into by investigating similar thermal behaviors of the DHW tank and by comparing annual results to each other when using Constant Temperature Set-point scenario. The annual results from the simulations are available at Table 2.

The results from Table 2 indicate that there are very little differences on annual level on the results with DHW

Table 2. Results from the Constant temperature heating scenario

\begin{tabular}{llll}
\hline & $\begin{array}{l}\text { Total } \\
\text { Heating } \\
{[\mathrm{MWh}]}\end{array}$ & $\begin{array}{l}\text { Average } \\
\text { Temperature } \\
{\left[{ }^{\circ} \mathrm{C}\right]}\end{array}$ & $\begin{array}{l}\text { Total } \\
\text { Costs } \\
{[€]}\end{array}$ \\
\hline Default 60min & 7.19 & 59.74 & 251.44 \\
Default 30min & 7.20 & 59.75 & 251.28 \\
Default 15min & 7.19 & 59.73 & 251.25 \\
Cat 60min & 7.20 & 59.78 & 245.42 \\
Cat 30min & 7.19 & 59.66 & 244.98 \\
Cat 15min & 7.18 & 59.60 & 244.84 \\
Standard 60min & 7.22 & 60.00 & 245.08 \\
Standard 30min & 7.21 & 60.00 & 244.78 \\
Standard 15min & 7.21 & 59.97 & 244.48 \\
\hline
\end{tabular}

60, 30 and 15 min withdrawal profiles. As the DHWcalc uses statistical methods in withdrawal profile creation, it is understandable that there are small differences on the results, but this could be considered as noise in the simulation as well.

\subsection{Behaviour of DHW heating controls}

This sections investigates the behaviour of the created DHW heating controls by looking into the DHW heating power frequency and cumulative frequency distributions on hourly heating scenarios. These results are presented in Figure 6 showing firstly the similarities between Constant Temperature Set-point and Linear Optimization scenarios, which rarely use maximum heating power and have more lower power consumption hours. This resemblance comes from the short optimization time in Linear optimization scenario, which makes both of them aim for lower water temperature in the DHW tank. Secondly, Figure 6 shows similarities of On-Off and ToU scenarios, which are more prone to have more maximum and minimum power periods and less intermediate power consumption. This relates to their control rules, as they both utilize maximum power until they reach the upper temperature limit, after which they do not use heating until they have reached the lower temperature set-point. The difference between these 2 control strategies lie in the maximum heating time-periods. On-Off scenario starts the maximum heating immediately once it has reached the lower temperature limit while ToU control keeps the DHW tank at the lower temperature point until the start of the cheaper night-time heating period. This is also the reason of their variations in $0-0.5 \mathrm{~kW}$ and $0.5-1.0 \mathrm{~kW}$ power consumption.

\subsection{Flexibility of DHW}

This section investigates the flexibility of DHW and the viability of few control mechanisms to provide DSM. First, the reference values for the flexibility are visible on Ta-

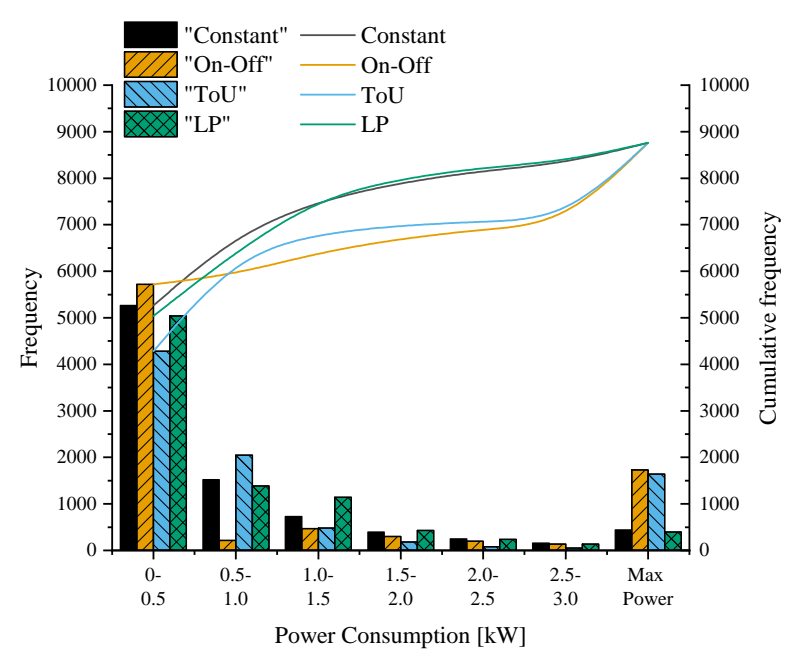

Figure 6. Frequency (bar) and cumulative frequency distributions (line) of the DHW heating scenarios in hourly time-scale 
Table 3. Annual results from On-Off, Time of Use and Linear optimization scenarios

\begin{tabular}{|c|c|c|c|c|c|c|c|c|c|}
\hline & $\begin{array}{l}\text { On-Off } \\
\text { Control }\end{array}$ & & & $\begin{array}{l}\text { Time of } \\
\text { Use }\end{array}$ & & & $\begin{array}{l}\text { Linear } \\
\text { Optimization }\end{array}$ & & \\
\hline & $\begin{array}{l}\text { Total } \\
\text { Heating } \\
\text { [MWh] }\end{array}$ & $\begin{array}{l}\text { Average } \\
\text { Temperature } \\
{\left[{ }^{\circ} \mathrm{C}\right]}\end{array}$ & $\begin{array}{l}\text { Total } \\
\text { Costs } \\
{[€]}\end{array}$ & $\begin{array}{l}\text { Total } \\
\text { Heating } \\
{[\mathrm{MWh}]}\end{array}$ & $\begin{array}{l}\text { Average } \\
\text { Temperature } \\
{\left[{ }^{\circ} \mathrm{C}\right]}\end{array}$ & $\begin{array}{l}\text { Total } \\
\text { Costs } \\
{[€]}\end{array}$ & $\begin{array}{l}\text { Total } \\
\text { Heating } \\
{[\mathrm{MWh}]}\end{array}$ & $\begin{array}{l}\text { Average } \\
\text { Temperature } \\
{\left[{ }^{\circ} \mathrm{C}\right]}\end{array}$ & $\begin{array}{l}\text { Total } \\
\text { Costs } \\
{[€]}\end{array}$ \\
\hline Default $60 \mathrm{~min}$ & 7.27 & 60.70 & 255.22 & 7.88 & 68.44 & 222.89 & 6.87 & 55.52 & 230.55 \\
\hline Default $30 \mathrm{~min}$ & 7.23 & 60.22 & 253.84 & 7.81 & 67.53 & 219.60 & 6.83 & 55.07 & 234.04 \\
\hline Default $15 \mathrm{~min}$ & 7.22 & 60.03 & 254.29 & 7.80 & 67.50 & 219.26 & 6.82 & 54.97 & 236.58 \\
\hline Cat $60 \mathrm{~min}$ & 7.27 & 60.62 & 249.50 & 7.96 & 69.53 & 219.70 & 6.87 & 55.53 & 224.47 \\
\hline Cat 30min & 7.23 & 60.11 & 248.58 & 7.88 & 68.44 & 216.28 & 6.83 & 55.01 & 227.77 \\
\hline Cat $15 \mathrm{~min}$ & 7.21 & 59.89 & 248.80 & 7.87 & 68.35 & 215.78 & 6.82 & 54.93 & 230.37 \\
\hline Standard 60min & 7.28 & 60.87 & 248.44 & 7.94 & 69.23 & 218.87 & 6.88 & 55.74 & 223.93 \\
\hline Standard 30min & 7.25 & 60.41 & 246.88 & 7.90 & 68.73 & 216.80 & 6.84 & 55.17 & 226.84 \\
\hline Standard $15 \mathrm{~min}$ & 7.23 & 60.21 & 245.85 & 7.90 & 68.72 & 216.42 & 6.83 & 55.08 & 229.25 \\
\hline
\end{tabular}

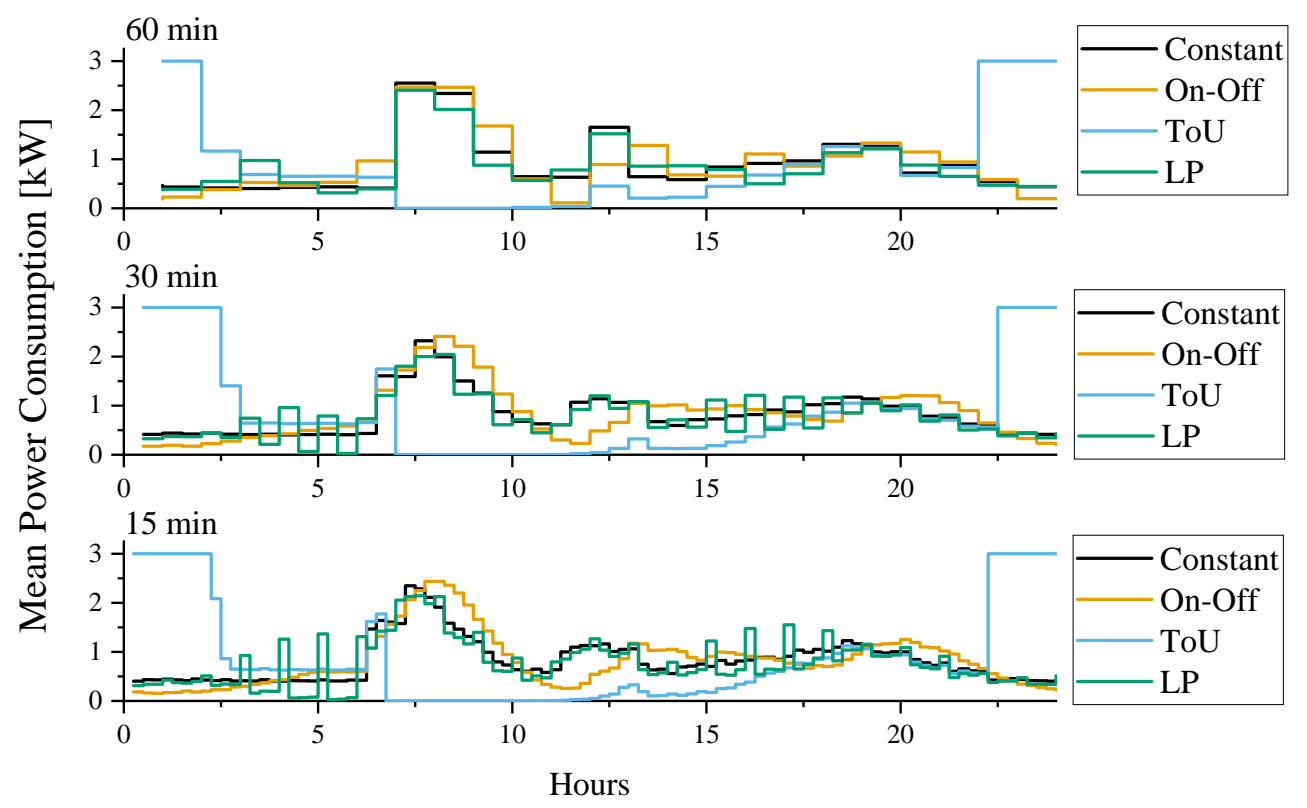

Figure 7. Comparison of the electricity load profiles of different heating scenarios with 60,30 and 15 min time resolution.

ble 2. The annual values for the other heating scenarios are available on Table 3 and the average hourly power for the DHW tank in Figure 7. The results from Table 3 indicate that changes between the time resolutions are generally small generating difference of less than $2 \%$ in heat demand or average hot water temperature, while the difference between cost can be slightly higher varying from -1.8 to $2.6 \%$.

Comparing different scenarios to each other, reveals the flexibility of the DHW source and the potential to participate in DSM programs. On annual level, the cheapest option seems to be night time charging with $T o U$ scenario, which is $13.5-16 \%$ cheaper than On-Off Control scenario and $2.1-7.3 \%$ cheaper than linear optimization scenario, while having 7.4-15.9\% higher electricity consumption and $10.8-24.8 \%$ higher average hot water temperature. This reveals the potential of storing energy to
DHW tank during the night-time. The higher hot water temperature is also beneficial in terms of comfort as $T o U$ scenario was the only one where the temperature of DHW tank was always over the lower temperature set-point, being able to provide enough hot water to use.

Looking into the average hourly heating loads from Figure 7 the night time charging of the DHW tank is clearly visible as it has higher electricity consumption during night hours and low consumption during the day. Similarly, the morning peak in the draw-off of hot water creates a heating peak in all scenarios, but $T o U$. Otherwise, Constant temperature set-point and Linear optimization scenarios had pretty similar load profiles, only difference being the occurring peaks with Linear optimization scenario in shorter time resolutions. These peaks will occur as the electricity price will remain the same for the whole hour, so the controller aims at increasing the temperature 

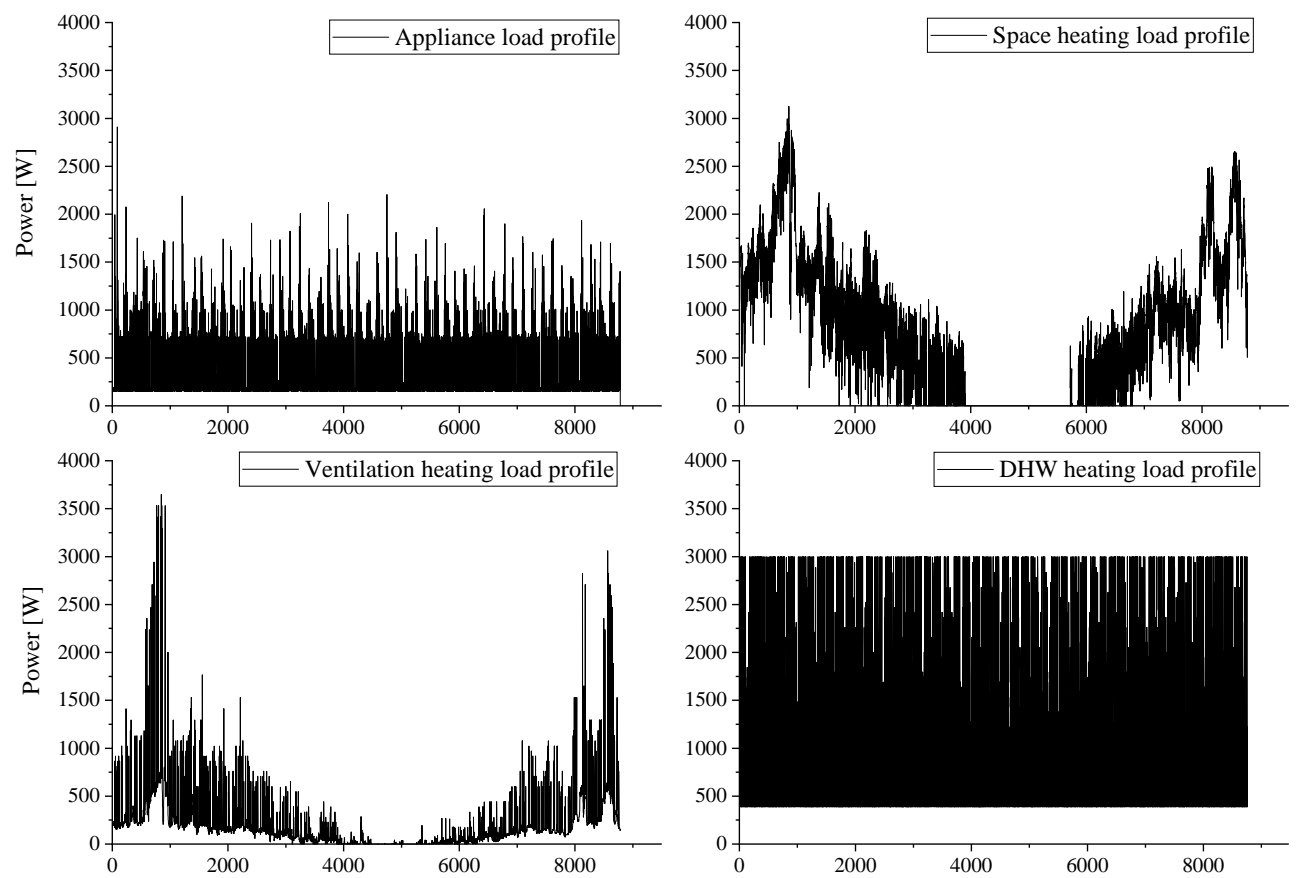

Figure 8. Comparison of various building loads

of the hot water on the earliest available time slot. On-Off control then had a delay on the heating compared to Constant and Linear optimization scenarios, as with On-Off controller the temperature of the water needs to drop under the lower temperature set-point before it applying the maximum heating power.

\subsection{Load profiles}

This part investigates the importance of integrating DHW model into the existing smart house model (Louis et al., 2016), with which it is possible to simulate appliance's load profiles, thermal behavior of the building and electric space and ventilation heaters. An example simulation was conducted with the smart house model and the achieved load profiles were compared to the load profile of the DHW heater (hourly constant temperature scenario) in Figure 8 and annual values in Table 4 . The simulated building was a detached house, with building characteristics similar to 2018 building type from (Pulkkinen et al., 2019) with randomly generated appliances.

Results from Table 4 show that the DHW heating has the highest electricity consumption in the example building, and from Figure 8 it becomes evident that DHW has

Table 4. Annual results from the example simulation

\begin{tabular}{lc}
\hline & $\begin{array}{c}\text { Annual Energy } \\
\text { Consumption [MWh] }\end{array}$ \\
\hline Appliances & 2.91 \\
Electric space heating & 7.08 \\
Electric ventilation heating & 1.50 \\
Electric DHW heating & 7.19 \\
\hline
\end{tabular}

highly varying, but seasonally rather constant load profile, similarly to appliances. Conversely, space and ventilation heating loads tend to require a lot of power during winter, but have low power demand in summer. This means that all these loads have their different characteristics and load profiles which while accumulated would have multiple impacting sources to the building's energy management.

\section{Conclusions}

The aim of this work was to create a functional, fully mixed DHW tank model to be integrated in an existing Markov-Chain smart house model and to investigate the flexibility of DHW load on 60, 30 and 15 min time resolutions and with 4 different heating controls. The behavior of the model was tested with using DHW withdrawal profiles created with $D H W$ calc program. The results indicate that the model was able to behave robustly with a Constant Temperature Set-point scenario in all tested time resolutions, showing little difference between their simulation results.

Comparing the results of different heating control scenarios from Table 3 the flexibility of the electricity consumption with DHW tank is visible in the ToU scenario results as it has the lowest costs and highest total heating energy consumption of the studied scenarios. Therefore, with ToU scenario it is possible to use DHW tank as an energy storage and charge it during the lower night time electricity prices. Yet, this behavior is contradictory as it reduces the efficiency of the system from electricity consumption point-of-view. The low performance from the Linear optimization scenario compared to $T o U$ was likely related to the short optimization time and mis- 
matches between the forecasted and actual energy withdrawals. These did not allow the optimized heater to utilize the thermal inertia of the DHW tank and lower electricity prices during the night as it did not expect a withdrawal from the tank early enough. Similarly, the difficulty in knowing the correct withdrawal of energy reduced the accuracy of the optimization. The final result showed the importance in integrating the DHW model with smart house model for allowing testing of new control mechanisms and different aggregated load profiles. Furthermore, in an integrated model all the separate electricity loads can be controlled together.

The future direction of the work is to finalize the integration of the smart house and DHW models, and start developing combined control mechanisms for them. Also the current DHW model should be developed to operate in lower time resolutions to allow also short-term power network testing, as well as expanded to include temperature stratification for increased accuracy and different DHW tank options. Consideration of improving the optimization with aggregated load profiles should be investigated as well. Also renewable energy generation and control mechanisms related to it should be added to the model.

\section{Acknowledgement}

This work was made possible through the University of Oulu strategic funding, the Energy as a Service Laboratory (EaaSLab) from the EU regional funding - EAKR (A74849), and the University of Oulu Graduate School (UniOGS).

\section{References}

K. Ahmed, P. Pylsy, and J. Kurnitski. Hourly consumption profiles of domestic hot water for different occupant groups in dwellings. Solar Energy, 137:516-530, 2016. doi:10.1016/J.SOLENER.2016.08.033.

U. Atikol. A simple peak shifting DSM (demand-side management) strategy for residential water heaters. Energy, 62:435440, 2013. doi:10.1016/j.energy.2013.09.052.

B. Baeten, T. Confrey, S. Pecceu, F. Rogiers, and L. Helsen. A validated model for mixing and buoyancy in stratified hot water storage tanks for use in building energy simulations. Applied Energy, 172:217-229, 2016. doi:10.1016/j.apenergy.2016.03.118.

EN 12831-3. Energy performance of buildings. Method for calculation of the design heat load. Part 3: Domestic hot water systems heat load and characterisation of needs, Module M82, M8-3. European Standard, 2017.

EN 15316-5. Energy performance of buildings. Method for calculation of system energy requirements and system efficiencies. Part 5: Space heating and DHW storage systems (not cooling), Module M3-7, M8-7. European Standard, 2017.

EN 50440. Efficiency of domestic electrical storage water heaters and testing methods. European Standard, 2015.
EN 60379. Methods for measuring the performance of electric storage water-heaters for household purposes. Standard, 2004.

E. Fuentes, L. Arce, and J. Salom. A review of domestic hot water consumption profiles for application in systems and buildings energy performance analysis. Renewable and Sustainable Energy Reviews, 81:1530-1547, 2018. doi:10.1016/j.rser.2017.05.229.

M. W. Jack, K. Suomalainen, J. J. W. Dew, and D. Eyers. A minimal simulation of the electricity demand of a domestic hot water cylinder for smart control. Applied Energy, 211: 104-112, 2018. doi:10.1016/j.apenergy.2017.11.044.

S. Ø. Jensen, A. Marszal-Pomianowska, R. Lollini, W. Pasut, A. Knotzer, P. Engelmann, A. Stafford, and G. Reynders. IEA EBC Annex 67 Energy Flexible Buildings. Energy and Buildings, 155:25-34, 2017. doi:10.1016/J.ENBUILD.2017.08.044.

U. Jordan and K. Vajen. Influence of the DHW load profile on the fractional energy savings: A case study of solar combisystem with TRNSYS simulations. Solar Energy, 69:197208, 2001. doi:10.1016/S0038-092X(00)00154-7.

J-N. Louis, A. Caló, K. Leiviskä, and E. Pongrácz. Modelling home electricity management for sustainability: The impact of response levels, technological deployment \& occupancy. Energy and Buildings, 119:218-232, 2016. doi:10.1016/j.enbuild.2016.03.012.

N. Lu. An Evaluation of the HVAC Load Potential for Providing Load Balancing Service. IEEE Transactions on Smart Grid, 3(3):1263-1270, 2012. doi:10.1109/TSG.2012.2183649.

Nord Pool. Historical Market Data, 2018. URL https://www.nordpoolgroup.com/ historical-market-data/. [Accessed 07.07.2020].

L. Paull, H. Li, and L. Chang. A novel domestic electric water heater model for a multi-objective demand side management program. Electric Power Systems Research, 80(12):14461451, 2010. doi:10.1016/j.epsr.2010.06.013.

J. Pulkkinen, J-N. Louis, and E. Pongrácz. Utilizing flexibility of electric heating in demand side management programs in Finland in 2050. In Proceedings of 11th International Conference on Applied Energy, Part 3, Sweden, 2019 (ICAE2019), volume 4, 2019.

J. Salpakari and P. Lund. Optimal and rule-based control strategies for energy flexibility in buildings with PV. Applied Energy, 161:425-436, 2016. doi:10.1016/j.apenergy.2015.10.036.

US Department of Energy. Benefits of Demand Response in Electricity Markets and Recommendations for Achieving Them, A report to the United States Congress Pursuant To Section 1252 of Energy Policy Act of 2005. Technical report, 2006. URL https://www.energy.gov/oe/downloads / benefits-demand-response-electricitymarkets-and-recommendations-achievingthem-report. [Accessed 07.07.2020]. 